
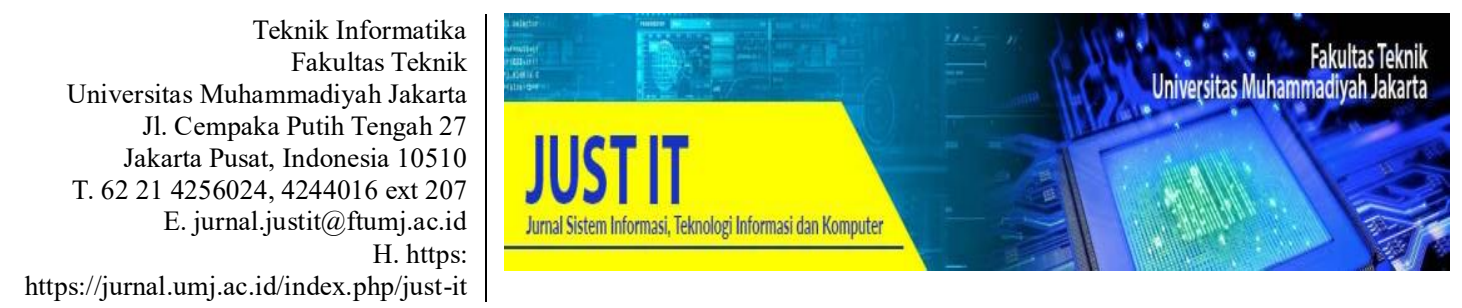

\title{
SISTEM APLIKASI TATA USAHA DI SDIT AL-GHOZALI CIBINONG-BOGOR
}

\author{
M.Barkah ${ }^{1}$, Thomas Afrizal ${ }^{2}$ \\ Informatika, Universitas Indraprasta PGRI, Jakarta-Indonesia \\ Jl. Nangka No 58, Tanjung Barat, Jakarta Selatan \\ Email:muhammadbarka17@gmail.com,thomztaurus.it@gmail.com
}

\begin{abstract}
Abstrak
Tujuan penelitian ini adalah untuk membangun sebuah aplikasi yang dapat membantu pihak TataUsaha dalam memproses data-data yang ada di sekolah, diantaranya data siswa, data guru, data nilai, data absensi. Proses-proses yang ada di SDIT Al-Ghozali masih menggunakan sistem manual atau tulis tangan, dengan berkembangnya teknologi yang mampu membantu dan mempermudah pekerjaan manusia sehingga peneliti melakukan penelitian dengan tujuan untuk mempermudah dalam proses berjalannya data di SDIT Al-Ghozali. Metode yang digunakan dalam penelitian ini yaitu menggunakan metode penelitian waterfall berdasarkan fakta dan pengkajian sehingga menghasilkan hal yang bermanfaat. Aplikasi ini dibuat menggunakan bahasa pemrograman java desktop dan menggunakan penyimpanan data di MySQL. Sistem yang telah dibuat digunakan untuk menyimpan data-data yang berkaitan dengan data siswa dan data guru.
\end{abstract}

Kata Kunci : Sistem Aplikasi Tata Usaha, Java Dekstop, MySQL

\begin{abstract}
The purpose of this study is to build an application that can help the Administration in processing data in schools, including student data, teacher data, grades data, attendance data. The processes in SDIT Al-Ghozali still use a manual or handwritten system, with the development of technology that can help and facilitate human work so that researchers conduct research with the aim to facilitate the process of running data at SDIT Al-Ghozali. The method used in this research is to use a waterfall research method based on facts and studies so as to produce useful things. This application is created using the java desktop programming language and uses data storage in MySQL. The system that has been made is used to store data relating to student data and teacher data.
\end{abstract}

Keywords: Administrative Application Systems, Java Desktop, MySQL.

\section{PENDAHULUAN Latar Belakang}

Perkembangan teknologi di Indonesia berkembang dengan cepat, seiring dengan dukungan pemerintah terhadap perusahaan yang menggunakan teknologi informasi. Teknologi informasi berkembang dengan sangat cepatnya dan banyak membantu manusia dalam menyelesaikan pekerjaan membuat teknologi informasi sangat disambut baik oleh banyak orang. Dalam proses pendidikan teknologi informasi sangat dibutuhkan karena semakin banyak sarana dan prasarana yang membutuhkan syarat-syarat menggunakan teknologi informasi.

SDIT Al-Ghozali merupakan sekolah yang sangat menyambut baik dari perkembangan teknologi informasi dan selalu berusaha meningkatkan sarana dan prasarana agar lebih memudahkan baik dari guru maupun siswa sehingga masalah birokrasi yang tidak kompleks guna membangun sekolah yang 
baik dan berguna untuk siswanya dikemudian hari. Dalam penyimpanan data SDIT AlGhozali masih menggunakan sistem manual yang membuat penyimpanan data bersifat rentan akan segala sesuatu yang dapat menyerang. Sehingga peneliti menggunakan kesempatan yang baik untuk membuat sesuatu yang bermanfaat bagi banyak orang khusus nya SDIT Al-Ghozali, dengan membangun sistem aplikasi tata usaha ini dapat membantu pihak tatausaha dalam hal penyimpanan data. Bapak Suhendi, Spd selaku kepala sekolah melaporkan sistem yang telah dibangun sangat membantu pihak tatausaha dalam penyimpanan data.

Peneliti meneliti dan memahami permasalahan yang terjadi di SDIT AlGhozali dan menjadi perhatian peneliti untuk menciptakan dan membuat sesuatu yang bermanfaat bagi SDIT Al-Ghozali, dan peneliti membuat penelitan dengan judul "Sistem Aplikasi TataUsaha di SDIT AlGhozali".

Sistem yang dibangun untuk menjadikan sistem yang berguna di bagian administrasi sekolah. SDIT Al-Ghozali masih menggunakan sistem administrasi secara manual. Administrasi aktivitas-aktivitas untuk mencapai tujuan, atau proses penyelenggaraan kerja untuk mencapai suatu tujuan yang telah ditetapkan (Daryanto, 2013).

Sistem adalah suatu jaringan kerja dari prosedur-prosedur yang saling berhubungan, berkumpul bersama-sama untuk melakukan kegiatan atau untuk melakukan kegiatan atau untuk melakukan sasaran tertentu(Hutahaean, 2017). Sistem yang dibangun dalam sebuah penelitian harus berdasarkan kumpulan masalah-masalah yang harus diselesaikan sehingga mempunyai tujuan.

Sistem dapat berupa abstrak atau fisik. Sistem yang abstrak adalah susunan gagasangagasan atau konsepsi yang teratur yang saling bergantung. Sedangkan sistem yang bersifat fisik adalah serangkaian unsur yang bekerja sama untuk mencapai suatu tujuan(Sutabri, 2012). Sistem yang telah dibangun harus disajikan secara rinci dan dimengerti oleh user, sehingga sistem dapat di pergunakan dan dimanfaatkan.

Sistem ini di buat agar menjadi sebuah aplikasi yang bermanfaat bagi banyak orang.
Aplikasi merupakan program-program yang dibuat oleh suatu perusahaan komputer untuk para pemakai yang beroperasi dalam bidang umum, seperti pertokoan, komunikasi, penerbangan, perdagangan, dan sebagainya(Kristanto, 2014).

\section{METODE PENELITIAN}

Metode penelitian yang di gunakan dengan tahapan-tahapan sebagai berikut :

a. Metode Penelitian

Metode penelitian langkah yang digunakan peneliti untuk mencari dan memperoleh data-data yang dibutuhkan sehingga dapat mempermudah peneliti dalam membangun sistem yang akan digunakan . Data yang diperoleh dapat digunakan dengan kebenaran data yang diperoleh langsung dari sumber terpercaya yaitu pihak sekolah SDIT Al-Ghozali. Metode penitian yang digunakan adalah waterfall dimana peneliti sangat mengandalkan keaslian data sesuai fakta yang ada di SDIT Al-Ghozali Cibinong Bogor.

b. Metode Pengumpulan Data

Metode pengumpulan data yang digunakan oleh peneliti untuk mendapatkan data-data dan informasi yang mendukung pengembangan sistem dan menunjang hasil akhir penelitian antara lain :

1). Analisa kebutuhan

Menganalisa kebutuhan yang akan membantu dalam menciptakan sistem yang ada di SDIT Al-Ghozali. Waktu yang habiskan dalam menganalisa kebutuhan ini dalam kurun waktu 2 minggu di bulan mei 2019. Peneliti mempelajari sistem yang berjalan di SDIT Al-Ghozali Cibinong Bogor sehingga dapat pengembangan sistem yang baik dan benar.

2). Desain Sistem

Dalam tahapan ini peneliti telah mendapatkan informasi yang akurat untuk menyempurnakan penelitian yang telah dikaji dan dipahami. Peneliti melakukan desain sistem yang membuat interface yang baik sehingga sistem yang digunakan memudahkan user dalam penggunaannya. Saat mendesain sistem peneliti menggunakan netbeans sebagai alat bantu dalam menciptakan sistem dan peneliti menggunakan MySQL dalam penyimpanan data yang kemudian mengganntikan sistem lama yang masih manual. 
Netbeans merupakan sebuah aplikasi Integrated Development Environment (IDE) yang berbasiskan Java dari Sun Microsystens yang berjalan di atas swing. Swing merupakan sebuah teknologi Java untuk pengembangan aplikasi desktop yang dapat berjalan pada berbagai macam platform seperti Windows, c. Linux, Mac OS dan Solaris. Sebuah IDE merupakan lingkup pemrograman yang diintegrasikan ke dalam suatu aplikasi perangkat lunak yang menyediakan Graphic User Interface (GUI), suatu kode editor atau text, suatu compiler, dan suatud. debugger(Wahana, 2015)

MySQL adalah satu jenis database server yang sangat terkenal dan banyak digunakan untuk membangun aplikasi web yang menggunakan database sebagai sumber dane. pengolahan datanya(Helmy, 2014).

3). Penulisan Kode Program

Dalam penulisan kode program peneliti melakukan dengan menggunakan bahasaf. program java. Java adalah nama sekumpulan teknologi untuk membuat dan menjalankan perangkat lunak pada komputer yang berdiri sendiri (standalone) ataupun pada lingkungan jaringan.

4). Operation dan maintenence

Pada operasi dan perawatan peneliti melakukan pengoperasian sistem yang telah dibuat menjadi sebuah aplikasi dan mencoba "Sistem Aplikasi Tatausaha di SDIT AlGhozali" dan memperbaiki sistem yang telah dicoba dan didapati kendala didalamnya.

5). Mengambil keputusan

Setelah melalui beberapa tahapan yang telah dilakukan maka pada bulan juli peneliti bersama Bapak Suhendi,S.Pd melakukan kesimpulan dan membuat keputusan bahwa ssistem yang telah dibangun akan digunakan sebagai alat bantu pihak tatausaha dalam melakukan penyimpanan dan pemasukan data baru.

\section{HASIL DAN PEMBAHASAN}

Dalam peraturan bisnis yang ada dalam SDIT Al-Ghozali maka sistem yang dibahas antara lain:

a. Pendataan Siswa

Siswa mengisi pendataan siswa dan data siswa, mengikuti kegiatan belajar, mengikuti ujian tengah semester, dan mengikuti ujian akhir semester

b. Pendataan Guru
Guru mengisi data pribadi dan bertanggung jawab atas mata pelajaran yang akan di berikan kepada siswa. Guru juga bertanggung jawab untuk memberikan informasi nilai yang akan di input kepada bagian administrasi tata usaha di SDIT Al-Ghozali

Pendataan Absensi

Guru bertanggung jawab untuk pengisian absensi siswa dan selanjutnya data akan dimasukan kedalam database absensi. Administrasi Tatausaha memasukan data absensi guru langsung kedalam database.

Pendataan Mata Pelajaran

Administrasi Tatausaha bertanggung jawab untuk pengisian data mata pelajaran yang dipelajari setiap kelas, dan guru yang bertugas untuk memberikan pelajaran.

Pendataan Nilai

Penilaian diambil dari nilai yang disepakati yaitu nilai tugas, nilai ujian tengah semester, dan nilai ujian akhir semester.

Laporan

Laporan berisi data-data yang telah terinput oleh Administrasi Tatausaha di SDIT AlGhozali.

Berikut ini merupakan penggambaran tentang sistem aplikasi tatausaha yang diusulkan di SDIT Al-Ghozali Cibinong Bogor secara keseluruhan dalam bentuk diagram konteks.

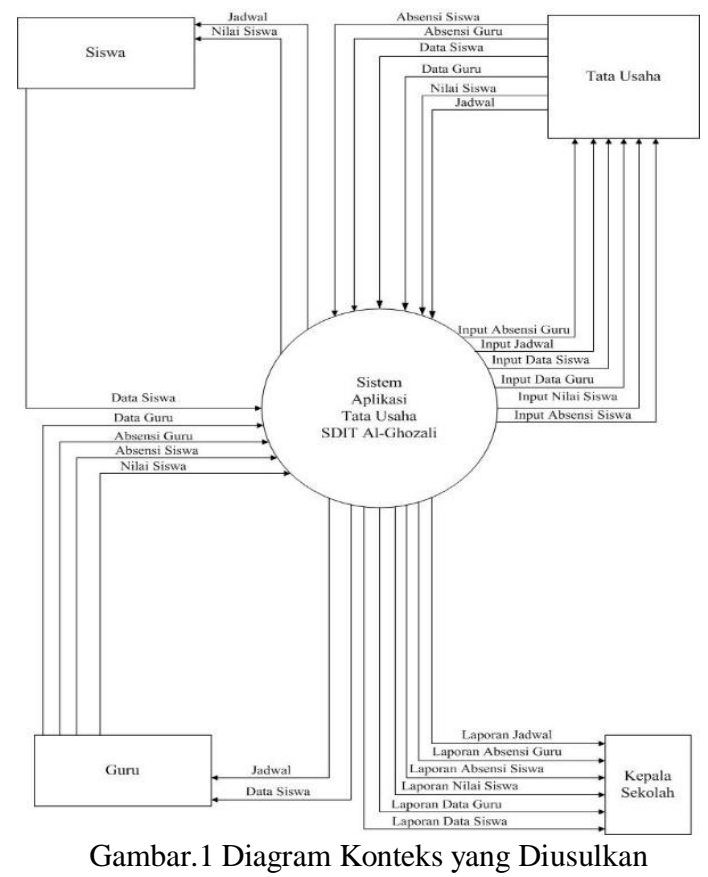

Normalisasi ke-3NF 


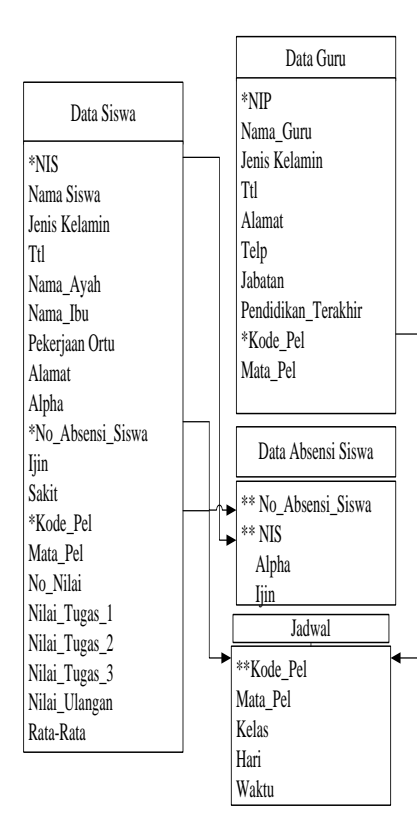

Gambar.2 Normalisasi ke-3NF

\section{Entity Relationship Diagram (ERD)}

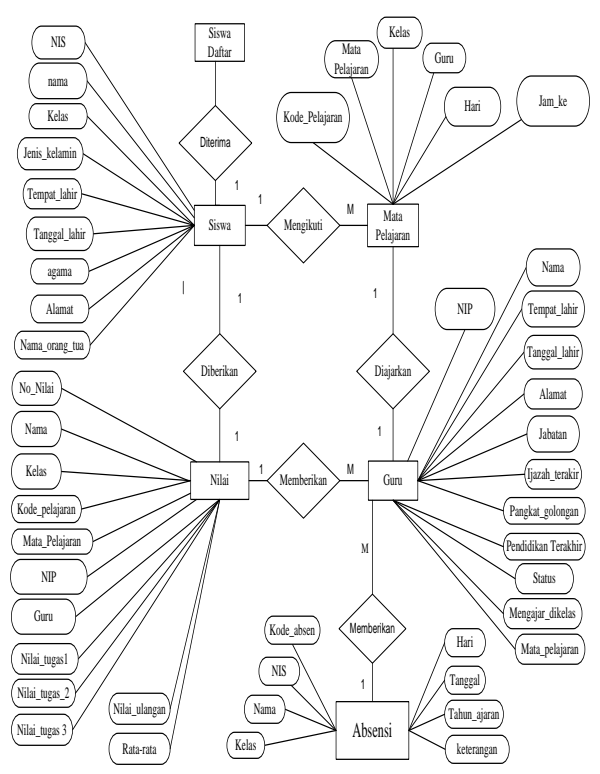

Gambar.3 ERD yang diusulkan

Tahapan selanjutnya yaitu peneliti membuat aplikasi dengan menggunakan aplikasi java netbeans, aplikasi yang telah dibuat ini menyempurnakan penelitian agar dapat dimanfaatkan oleh SDIT Al-Ghozali.

\section{Tampilan Layar \\ Tampilan Menu Login}

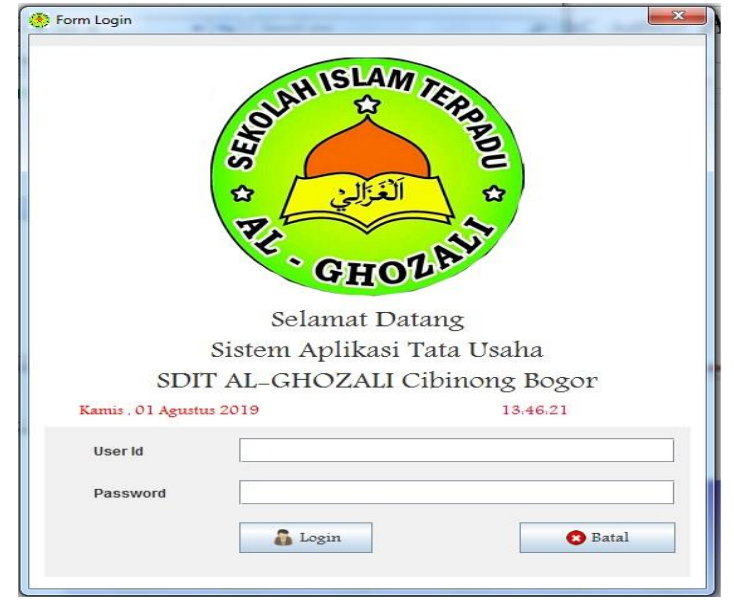

\section{Gambar 4. Login}

Tampilan ini akan muncul pada saat aplikasi dijalankan dan pengguna harus mengisi data yang telah dibuat, maka pengguna akan dapat masuk dan menjalankan aplikasi tatausaha.

\section{Tampilan Menu Utama}

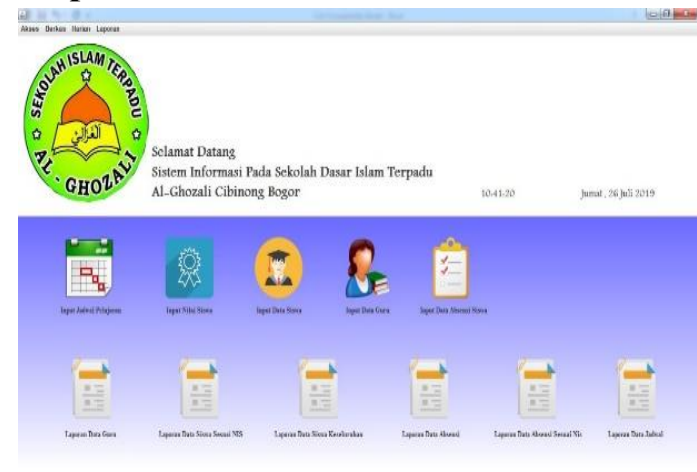

\section{Gambar 5. Menu Utama}

Dalam menu utama ini pengguna dapat memilih data yang akan diproses sesuai dengan gambar icon yang ada pada menu utama. Terdapat icon-icon yang dapat membantu pengguna untuk proses data yang akan digunakan.

\section{Tampilan Input Data Siswa}

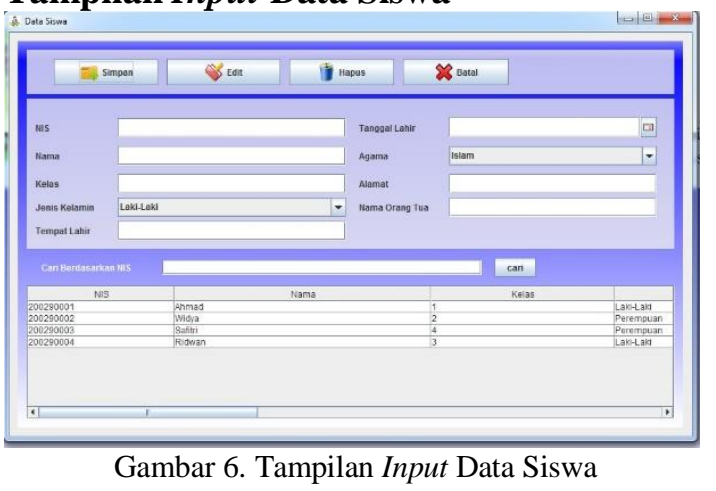


Dalam tampilan ini pengguna dapat mengisikan data-data yang diperlukan dalam melengkapi data siswa yang akan disimpan kedalam database.

\section{Tampilan Input Data Guru}

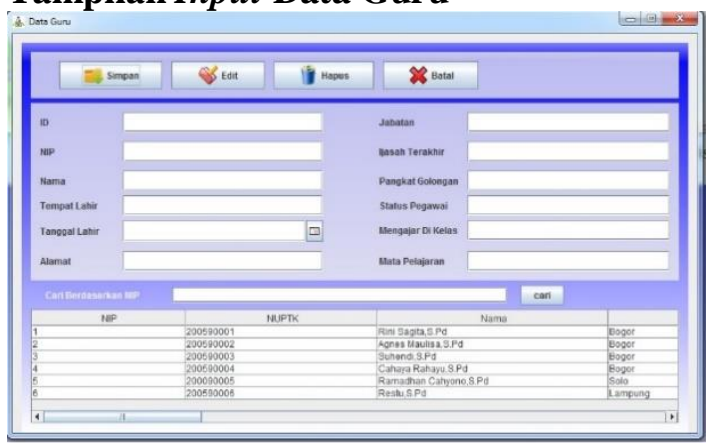

Gambar 7. Tampilan Input Data Guru

Pada proses ini pengguna atau administrasi tatausaha melakukan pengisian data guru untuk penyimpanan kedalam database.

\section{Tampilan Input Jadwal Belajar Mengajar}

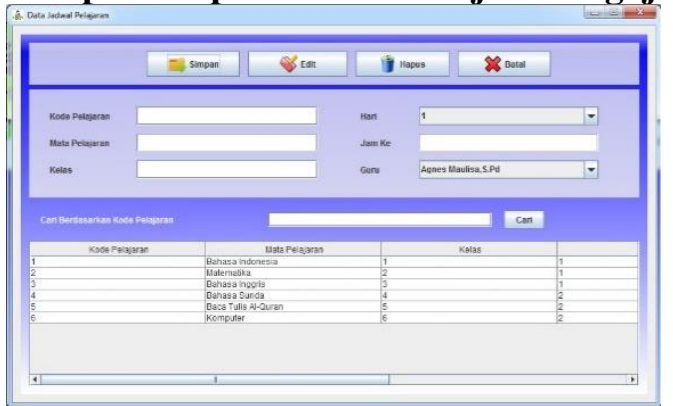

Gambar 8. Tampilan Input Jadwal Belajar Mengajar

Pada tahapan ini administrasi tatausaha dapat mengisikan mata pelajaran yang diajarkan oleh guru kepada siswa-siswi yang ada di SDIT Al-Ghozali. Selanjutnya tatausaha akan menginformasikan kepada siswa-siswi terkait jadwal mata pelajaran yang akan diikuti oleh siswa-siswi.

\section{Tampilan Input Absensi Siswa}

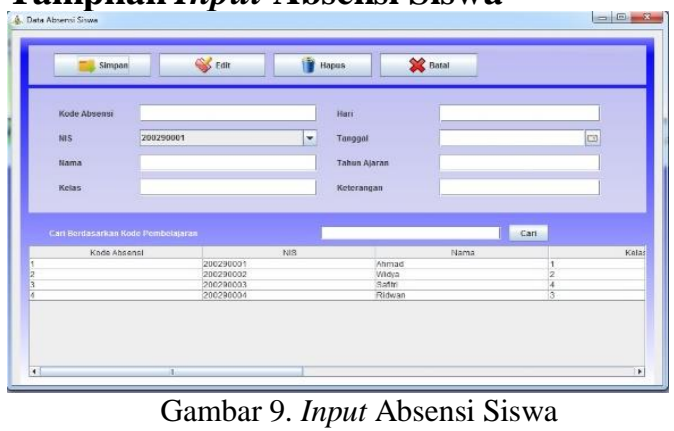

Administrasi akan melakukan pengisian absensi siswa dan akan menyimpannya kedalam database.

\section{Tampilan Input Absensi Guru}

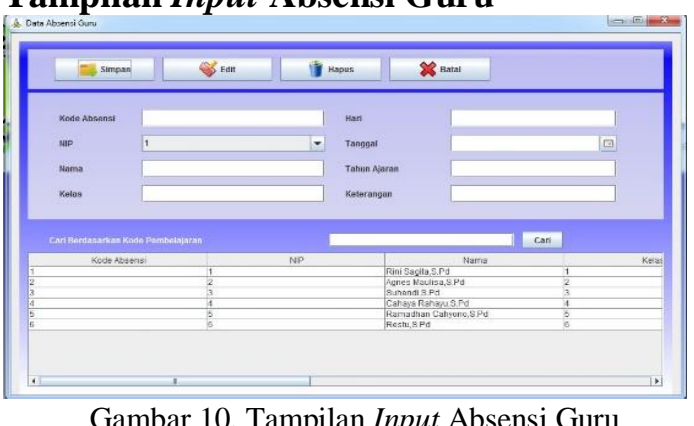

Pada tahapan ini administrasi tatausaha melakukan pengisian absensi guru sesuai dengan kehadiran guru pada hari kerja.

\section{Tampilan Input Nilai Siswa}

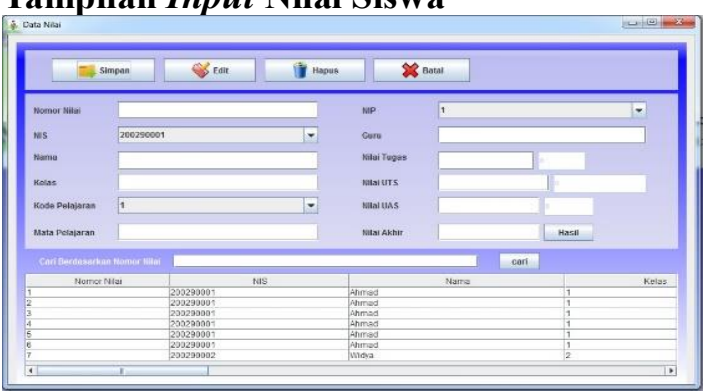

Gambar 11. Tampilan Data Pengobatan Hewan

Siswa yang telah mengikuti kegiatan belajar mengajar akan mendapatkan nilai dari guru pengajar dan nilai-nilai yang didapatkan oleh setiap siswa akan disimpan dalam database secara keseluruhan.

\section{Tampilan Laporan Data Siswa}

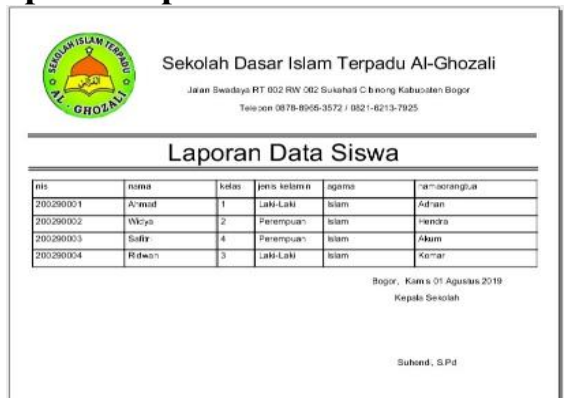

Gambar 12. Laporan Data Siswa

Laporan ini memuat data-data siswa yang telah diinput oleh administrasi tatausaha. 
Tampilan Laporan Data Guru

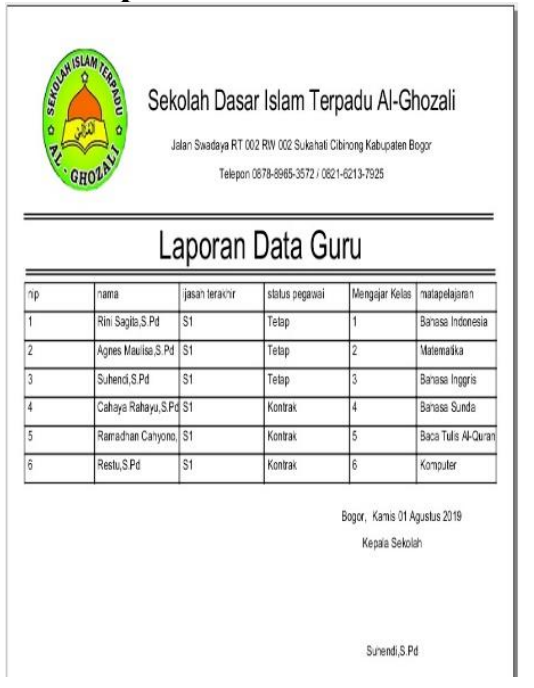

Gambar 13. Laporan Data Guru

Data-data guru yang telah diinput akan ditampilakan dalam laporan keseluruhan.

\section{Tampilan Laporan Jadwal Belajar Mengajar}

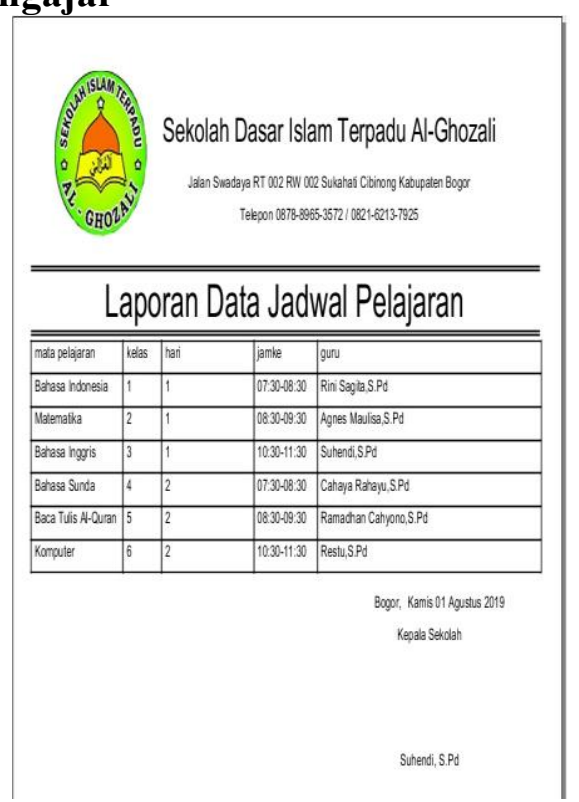

Gambar 14. Laporan Jadwal Belajar Mengajar

Laporan jadwal belajar mengajar ini dapat menjadi sumber informasi dalam kegiatan belajar mengajar.
Tampilan Laporan Absensi Siswa

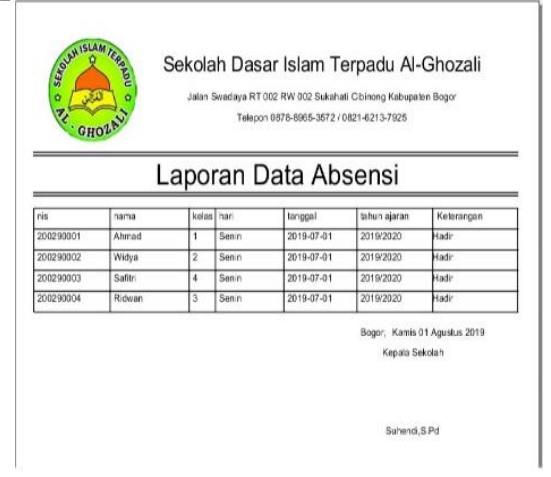

Gambar 15. Laporan Absensi Siswa

Laporan dari kehadiran siswa, akan ditampilkan dalam laporan data absensi siswa.

\section{Laporan Absensi Guru}

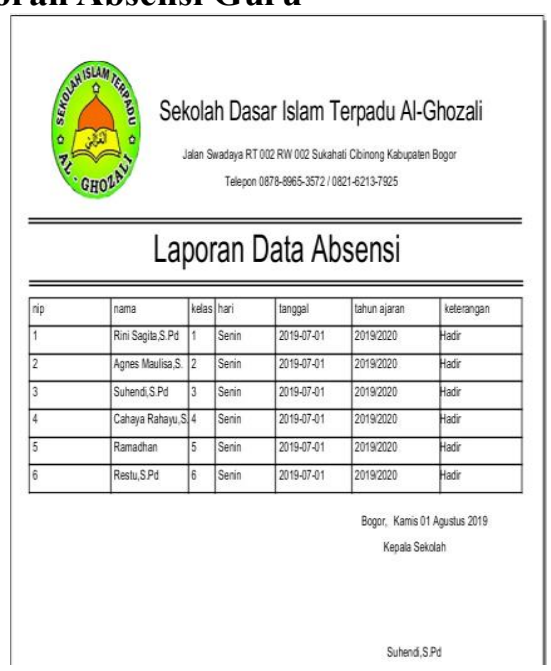

Gambar 16. Laporan Absensi Guru

Laporan dari kehadiran guru, akan ditampilkan dalam laporan data absensi guru.

\section{Tampilan Laporan Nilai Siswa}

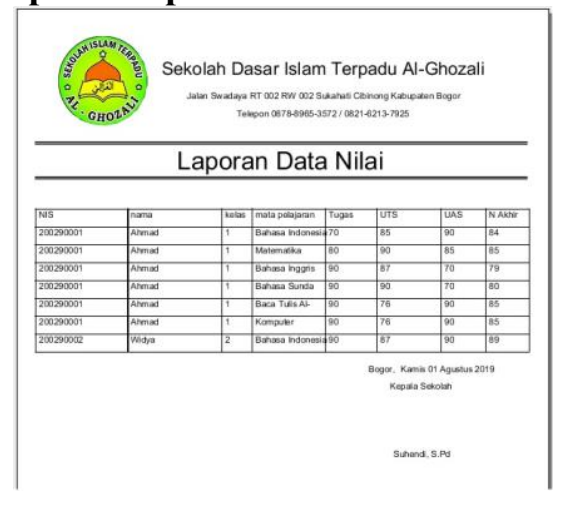

Gambar 16. Laporan Nilai Siswa 
Nilai-nilai siswa selama kegiatan belajar mengajar akan dapat diinformasikan dari laporan yang didapat dari laporan nilai siswa.

\section{KESIMPULAN}

\section{a. Simpulan}

Dalam penelitian yang telah dilakukan, maka dapat ditarik kesimpulan bahwa sistem aplikasi tata usaha yang telah dibuat sebagai berikut :

1). Sistem aplikasi tata usaha dirancang untuk memudahkan administrasi tatausaha dalam memproses data-data yang digunakan di SDIT Al-Ghozali

2). Sistem lama yang masih menggunakan sistem manual akan menjadi pokok bahasan dalam membangun sistem yang baru.

\section{b. Saran}

1). Untuk mempermudah dan melakukan perawatan sistem peneliti menyarankan kepada SDIT Al-Ghozali untuk melakukan pengecekan data secara berkala didalam database

2). Upaya dalam kemajuan teknologi, aplikasi harus terus dikembangkan agar dapat lebih memudahkan dalam prosesan data.

\section{Daftar Pustaka}

Daryanto, H. . (2013). Administrasi dan Manajemen Sekolah. Bandung: Informatika.

Helmy, R. S. (2014). Pengolahan Database $S Q L$ dengan Java. Jakarta: Elex Media Komputindo.

Hutahaean, J. (2017). Konsep Sistem Informasi. Jurnal Administrasi Pendidikan.

Kristanto, A. (2014). Perancangan Sistem Informasi dan Aplikasinya. Yogyakarta: Graha Ilmu.

Sutabri, T. (2012). Analisis Sistem Informasi. Analisa Sistem Informasi.

Wahana, K. (2015). Membangun Sistem Informasi Java dengan NetBeans dan MySQL. Andi Ofset. 